\title{
SITUAÇÃO ATUAL DAS ESTATÍSTICAS OFICIAIS RELATIVAS À MORTALIDADE POR CAUSAS EXTERNAS*
}

\author{
Maria Helena P. de Mello Jorge**
}

\begin{abstract}
MELLO JORGE, M.H.P. de. Situação atual das estatísticas oficiais relativas à mortalidade por causas externas. Rev. Saúde públ,, S. Paulo, 24: 217-23, 1990.
\end{abstract}

\begin{abstract}
RESUMO: Foi realizado estudo com base nos dados de uma pesquisa que analisou 550 mortes de crianças menores de 15 anos, residentes no Município de Sāo Paulo, SP (Brasil), e ocorridas em 1985 por todos os tipos de acidentes e violências. Objetivou-se comparar entre si as informaçōes existentes no Instituto de Medicina Legal (IML) e as constantes da Fundação Sistema Estadual de Análise de Dados (SEADE), responsável pelas estatísticas oficiais em São Paulo, com a opinião do investigador - formada com base em toda a informação adicional possível, de modo a: analisar a fidedignidade das estatísticas oficiais quanto à causa básica da morte; e conhecer a possível deficiência da transcrição das informaçōes do IML para a Fundação SEADE, quanto à mesma causa. Os resultados permitiram mostrar que: a informaçāo existente no IML esteve bastante próxima da opiniảo do investigador $(71,54 \%)$ quando se trabalhou em nível de categoria da Classificação Internacional de Doenças (CID-9), chegando a $84,77 \%$ quando se considerou o nível de agrupamento; as estatísiticas oficiais, em relação à opiniăo do investigador, são mais fidedignas quando analisadas em nível de agrupamento do que de $3^{\circ}$ dígito (respectivamente $67,13 \%$ e 24,05\% de concordância); a comparação entre o IML e a Fundação SEADE mostrou que, relativamente às categorias da CID-9, só existe $40 \%$ de concordância; dado que se eleva a $75 \%$ quando os agrupamentos săo analisados. Esses valores comprovam a hipótese formulada de que o IML, embora possua um arquivo com informações pormenorizadas, não as transfere à Fundação SEADE, diminuindo assim a fidedignidade das estatísticas oficiais, à medida que se detalhe cada causa de morte. Sugere-se um maior entrosamento entre essas Instituiçð̄es para que estatísticas de melhor qualidade, relativamente às causas externas de morte, venham a ser produzidas.
\end{abstract}

DESCRITORES: Causa de morte. Acidentes. Violência. Registros de estatísticas vitais.

\section{PRELIMINARES}

Pode-se dizer que desde Graunt, 1662, as estatísticas oficiais de mortalidade sảo geradas a partir dos dados coletados nas Declaraçōes de Obitos passadas pelos médicos.

Com relação às mortes por causas externas, a lei determina que esses atestados sejam passados por médicos legistas, após necropsia. O fluxo seguido por esses documentos faz com que os mesmos, do Instituto Médico Legal (IML), pelos Cartórios do Registro Civil, cheguem aos órgãos responsáveis pela elaboração das estatísticas - especificamente no caso de São Paulo à Fundação SEADE (Sistema Estadual de Análise de Dados).

Em trabalhos anteriores foi medida a deficiência da informação oficial relativa às causas de morte em geral (Milanesi e Laurenti ${ }^{11}, 1964$ e Fonseca e Laurenti $i^{13}$ 1974) e sabe-se, portanto, que a qualidade das informaçōes contidas nas Declaraçóes de Óbitos deixa ainda a desejar, apesar de cursos e bibliografia especializada virem sendo efetuados e produzidos com esse objetivo (Ministé- rio da Saúde ${ }^{12}$, 1977; Laurenti e Mello Jorge 5 , 1987)

Especificamente no que toca às causas externas, a qualidade é também, de alguma forma, discutível, principalmente em função de os legistas, por temor, talvez, de envolvimento com a justiça ou com a polícia (Laurenti e Mello Jorge ${ }^{5}, 1987$ ), colocarem no atestado somente a "causa médica" da morte, ou seja, a natureza do traumatismo ou lesão que levou ao óbito, grande parte das vezes, sem qualquer referência à verdadeira (ou mesmo presumida) causa básica da morte, definida pela Organização Mundial da Saúde como o "tipo de acidente ou violência que ocasionou as lesões que levaram d morte" (CID ${ }^{1}, 9^{a}$ Revisão, 1975). Ainda mais, por desconhecimento ou negligência do funcionário que preenche esse documento (o que na grande maioria das vezes não é feito pelo médico), a informação sobre o evento violência (itens $37,38,39$ da Declaração de Óbito) não é transcrita na mesma, embora existente no IML, que, em muitos casos, tem até mesmo uma cópia do Boletim de Ocorrência Policial. Fatos como esses fazem com que as estatísticas oficiais por essas causas apresentem-se, pelo menos, incompletas, para não dizer, incorretas.

\footnotetext{
* Parte da pesquisa "Investigação sobre a mortalidade por acidentes e violência na Infância". Tese de Livre Docência apresentada à Faculdade de Saúde Pública da Unıversidade de São Paulo, em 1988.

* Departamento de Epidemiologia da Faculdade de Saúde Pública da Universidade de São Paulo - Av. Dr. Arnaldo, 715 - 01255 - São Paulo, SP - Brasil.
} 
Problemas dessa natureza têm gerado o fato de que, em nível de publicaçōes oficiais do Ministério da Saúde ${ }^{13}$ (1977/1985), mesmo onde as causas de morte são classificadas em grandes grupos (CID$\left.\mathrm{BR}^{2}, 1975\right)$, o conhecimento quanto ao tipo de acidente ou violência que levou à morte fique bastante prejudicado. A Tabela 1 mostra que, em 1985, em algumas capitais brasileiras, os percentuais relativos às causas, que se sabiam externas, mas que se ignoravam se eram acidentais ou intencionais apresentaram-se bastante variáveis, chegando a atingir valores maiores que $40 \%$ em locais como Rio de Janeiro, Porto Alegre e Goiânia.

Pesquisa sobre a mortalidade por acidentes e violências em menores de 15 anos residentes no $\mathrm{Mu}$ nicípio de São Paulo, realizada com o patrocínio da Organização Panamericana de Saúde (Mello Jorge $^{18}$, 1988) e calcada na metodologia utilizada pelas Investigaçōes da Mortalidade do Adulto (Puffer e Griffith ${ }^{15}, 1968$ e Guimarães e col.4, 1979) e Mortalidade na Infância, (Puffer e Serrano ${ }^{16}$, 1973), contou com a adição de dados procedentes de relatórios de necropsias, consultas aos processos de inquéritos em Delegacias de Polícia, prontuários hospitalares, notícias de jornal e, principalmente, entrevistas nas casas das crianças que haviam falecido durante o ano de 1985. Dessa forma, permi-

\section{TABELA 1}

Percentual de causas externas de tipo ignorado em relação do total de 6 bitos por causas externas em capitais brasileiras, 1981, 1983, 1985

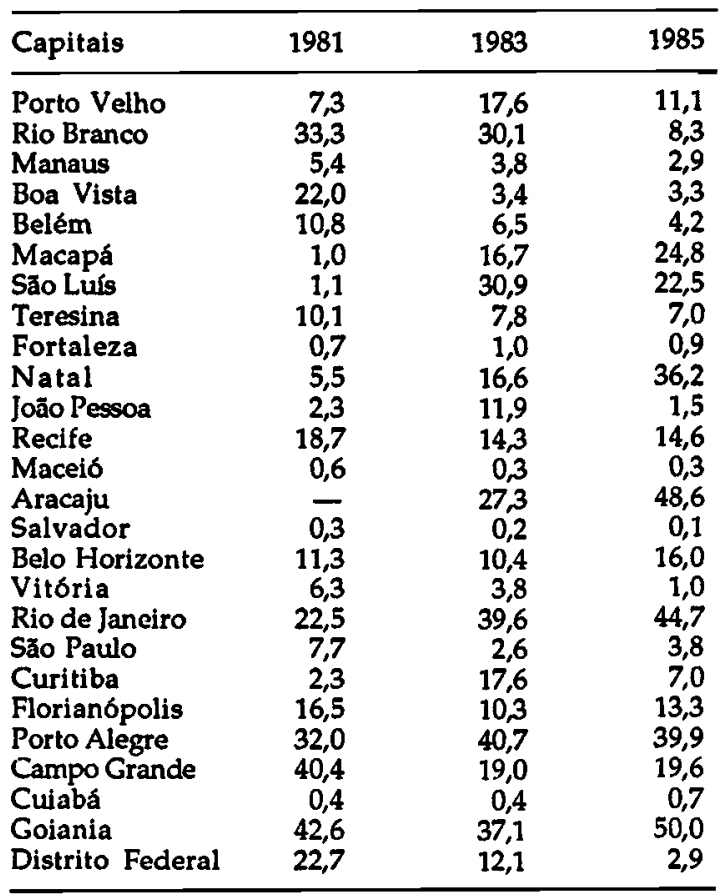

Fonte: Ministério da Saúde. Estatísticas de Mortalidade, Brasil, 1981, 1983, 1985 (Dados brutos). tiu ao investigador uına valiosa contribuição para - conhecimento das causas que levaram essas crianças à morte, em seu maior detalhamento possível (formando o que se convencionou chamar de opiniăo do investigador).

Além disso, o manuseio constante dos formulários do IML tem tornado possível conhecer a riqueza de informaçð̄es que existe nessa Instituição, a respeito de cada caso que ali chega para ser necropsiado (Mello Jorge, ${ }^{8,9,10} 1979,1982,1988$ ).

Diante desse quadro tridimensional - opinião do Investigador, IML e SEADE -, optou-se por comparar essas três fontes, no sentido de mostrar, em função das informações existentes em cada uma delas, como foi (ou seria) codificada a causa básica da morte de cada caso pertencente à investigação realizada, permitindo, em última análise, mensurar a fidedignidade da causa básica da morte (oficial), relativamente ao universo trabalhado. foram:

Assim, pois, os objetivos da presente pesquisa - comparar a informação oficial sobre óbitos por causas externas gerada na Fundaçăo SEADE, pelas Declaraçōes de Öbitos, com a existente no IML e aquela obtida com a adição de dados complementares, através da pesquisa (opinião do investigador);

- mensurar a concordância da informação sobre a causa básica nas três fontes estudadas;

- mensurar a fidedignidade da informação oficial - SEADE - e da existente no IML, tomando como referencial a causa básica "real" obtida com os dados da pesquisa.

\section{MATERIAL E MÉTODO}

O material utilizado foi constituído do universo de 550 6bitos de crianças menores de 15 anos, residentes no Município de Sāo Paulo, cuja morte, por causa externa, ocorreu em 1985. Foram realizadas cntrevistas domiciliares, nos hospitais onde essas crianças foram atendidas (nos casos de óbitos hospitalares), nas Delcgacias de Polícia e no próprio IML, onde foi possível copiar o laudo necroscópico relativo a cada caso. O conhecimento de toda essa informação possibilitou ao Investigador, conhecendo, em profundidade, cada caso, praticamente reconstituir as Declaraçōes de Óbitos correspondentes, colocando nesse documento a nova informação ("opinião do investigador") e que se considcrou como a causa básica real da morte de cada criança.

A metodologia adotada foi a scguinte:

Opinião do Investigador: os óbitos tiveram suas causas codificadas, com base em todas as infor- 
maçð̃es adicionais possíveis. Os códigos foram dados de acordo com a CID ${ }^{1}$ - 9 Revisão, 1975, utilizando as regras de mortalidade da mesma (em nível de quarto dígito), sendo que, para os objetivos do presente trabalho, utilizaram-se os códigos medidos somente em nível de terceiro dígito.

Fundação SEADE: dentre todas as Declaraçōes de Óbitos registradas no Município de São Paulo, em 1985, para todas as idades (aproximadamente 60.000), foram retiradas aquelas referentes às 550 crianças menores de 15 anos e, de cada uma delas, copiado o código dado à causa básica da morte por essa Instituição. Esses dados correspondem às estatísticas oficiais de São Paulo.

Instituto Médico Legal (IML): da ficha de entrada do corpo no IML, da qual constam as informaçбes de identificação do corpo, do local onde o mesmo se encontrava e da história do acidente que levou à morte (em algumas vézes até mesmo acompanhado do Boletim de Ocorrência Policial - BO - conforme já salientado), foi extraída a informação relativa à causa básica da morte. Esta foi codificada, rigorosamente, de acordo com $\mathrm{CID}^{1}-9^{\mathrm{a}}$ Revisão, 1975.

Elaborou-se uma listagem - caso a caso - colocando em três colunas os códigos atribuídos às causas básicas de óbitos, para cada caso, segundo as informaçoes de cada uma das fontes estudadas: Opinão do Investigador - SEADE - IML.

Numa segunda etapa, elaborou-se uma tabela de concordância (nível de terceiro dígito ou categoria e nível de agrupamento da CID-9 - Classificação Suplementar de Causas Externas), visando exatamente a estabelecer em que medida essas fontes codificavam as mortes de igual maneira: comparando as três fontes entre si e, em seguida, duas a duas.

O pressuposto básico do qual se partiu foi o de que o ganho de informação, com a metodologia utilizada na pesquisa (maior do que a existente nas outras fontes), permitiu uma melhor caracterização da causa básica da morte.

A primeira hipótese levantada foi a de que as informaçōes contidas no IML levariam a uma causa básica muito proxima daquela encontrada pelo investigador. Por outro lado, havia também a suposição de que, em pequeno número de casos, todas as informaçōes do IML eram passadas ao SEADE, via Declaração de Óbito, ocasionando, dessa forma, uma informação oficial menos precisa e detalhada.

Cabe ainda ressaltar que, com relação ao material analisado:

- As Declaraçōes de Óbitos de 1985, à época da coleta da informação, estavam ainda sendo manu- seadas pelos funcionários do SEADE e essa causa foi, talvez, a responsável pelo fato de não terem sido localizadas 48 Declaraçōes $(8,73 \%)$ das mortes das 550 crianças estudadas.

Em razão de os três casos pertinentes à categoria "Outros tipos de morte" (casos de "trauma da mãe afetando a criança") terem sido colocadas no trabalho, com finalidade apenas de conhecer o quadro epidemiológico total (apesar da disposição contrária da CID), foram os mesmos voluntariamente excluídos da tabela de comparação de causas.

O material, portanto, com que se trabalhou, nesta etapa, totalizou 499 casos de óbitos.

\section{RESULTADOS E DISCUSSÃO}

A Tabela 2 mostra os resultados obtidos quando se compararam as causas básicas das três fontes estudadas.

Essa Tabela mostra que a concordância entre as três fontes, em nível de terceiro dígito, foi igual a $23,45 \%$ e, em nível de agrupamento, a $66,13 \%$. A opinião do investigador concordou com a do IML, excluindo o SEADE, em $48,10 \%$, e o SEADE e o $\mathrm{IML}$, independentemente da opiniăo do investigador, concordaram em 15,83\% (quando se considerou categoria) e em $8,62 \%$ (quando se considerou o agrupamento da CID).

Por outro lado, a opinião do investigador foi codificada diferentemente do IML e do SEADE em

\section{TABELA 2}

Concordância entre as fontes: opinião do investigador (O.I.), SEADE e IML quanto à causa básica da morte, segundo nivel de comparação (óbitos por causas externas em menores de 15 anos residentes no Município de São Paulo, 1985) (Nº \%).

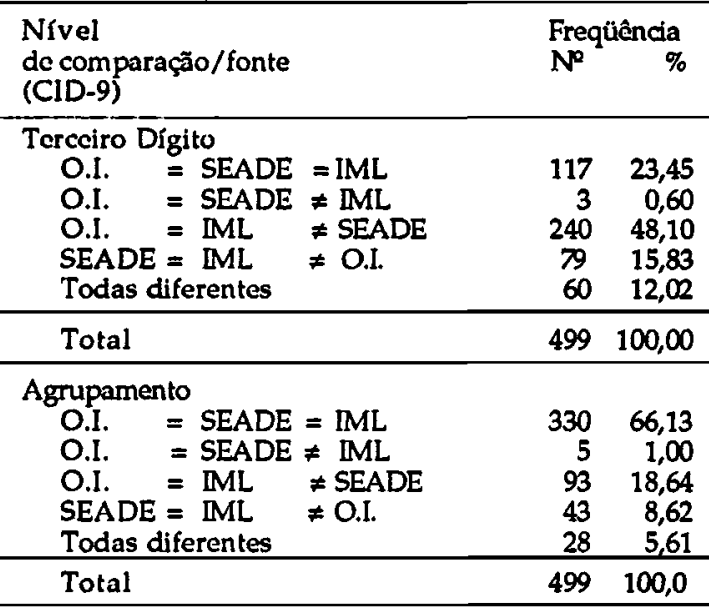


$12,02 \%$ e $5,61 \%$ quando o nível de comparação foi, respectivamente, categoria e agrupamento.

Outro tipo de análise que pôde ser feita é a relativa à verificação da concordância das fontes, duas a duas, independentemente da terceira (Tabela 3).

Os valores obtidos na Tabela 3, somados aos da Tabela 2, comprovam as hipóteses levantadas, a medida que evidenciam que:

- a opinião do investigador 'foi igual à causa da morte mostrada pelo IML em, praticamente, $72 \%$ $(71,54 \%)$ quando a análise foi feita em nível de terceiro dígito e passou a um valor de quase $85 \%$, quando os agrupamentos foram tomados como referência;

- a concordância baixou para $24,05 \%$ (em nivel de terceiro dígito) e $67,13 \%$ (em nível de agrupamento) quando foi feita entre a opiniăo do investigador e o SEADE;

- a comparaçăo IML/SEADE, sem levar em conta a opinião do investigador, mostrou valores de $39,28 \%$ e $74,75 \%$ (respectivamente para categoria e agrupamento), tornando clara a idéia inicial de que a informação enviada à Instituição responsável pelas estatísticas oficiais é incompleta, permitindo uma codificaçăo da causa, muitas vezes, somente nas categorias residuais. Isso é o que se verifica, por exemplo, nos casos de "atropelamento", onde o IML, ao preencher a Declaraçăo de Óbito, coloca somente a informação de que se trata de "acidente de trânsito sem especificação" (categorias diferentes, mas pertencentes ao mesmo agrupamento da CID ${ }^{1}-92$ Revisão). $O$ mesmo fato ocorre com relação aos homicídios, para os quais o IML, tendo capacidade para detalhar a informação (fornecendo a modalidade ou meio pelo qual o homicidio foi cometido), preenche a Declaração somente com o termo genérico "Homicídio" (codificação em categoria residual).

\section{TABELA 3}

Concordância entre as fontes opinião do investigador, SEADE e IML, duas a duas, quanto à causa básica da morte, segundo nível de comparaçāo (6bitos por causas externas em menores de 15 anos residentes no Munićpio de São Paulo, 1985) (N e \%).

\begin{tabular}{|c|c|c|}
\hline $\begin{array}{l}\text { Nivel de } \\
\text { comparaça/fonte }\end{array}$ & \multicolumn{2}{|c|}{$\begin{array}{l}\text { Freqüência } \\
N^{0} \%\end{array}$} \\
\hline $\begin{array}{l}\text { Terceiro Digito } \\
\text { O.I. }=\text { SEADE } \\
\text { O.I. }=\mathbb{M} L \\
\text { SEADE }=\mathbb{M} L\end{array}$ & $\begin{array}{l}120 \\
357 \\
196\end{array}$ & $\begin{array}{l}24,05 \\
71,54 \\
39,28\end{array}$ \\
\hline $\begin{array}{l}\text { Agrupamento } \\
\text { O.I }=\text { SEADE } \\
\text { O.I. }=\mathbb{M L} \\
\text { SEADE }\end{array}$ & $\begin{array}{l}335 \\
423 \\
373\end{array}$ & $\begin{array}{l}67,13 \\
84,77 \\
74,75\end{array}$ \\
\hline
\end{tabular}

Esses casos ilustram o que já foi dito anteriormente de que o IML não fornece ao SEADE dados completos sobre cada caso, nem este vai àquela Instituiçăo em busca do detalhamento desejável. Esse fato gera um acúmulo de casos nas categorias residuais (em nível de terceiro dígito), mas as diferenças, entretanto, tendem a se minimizar quando se trabalha em nivel de agrupamento.

Problemas como esse, todavia, não ocorrem somente em Såo Paulo. Acredita-se, mesmo, que em outras áreas do Brasil a situação seja mais grave. Peixoto 14, 1987, elaborou estudo para o Estado de Santa Catarina pelo qual mostrou, como e em que medida, as informaçôes sobre os óbitos por causas externas que chegam à Secretaria da Saúde daquele Estado podem ser melhoradas, quantitativa e qualitativamente, somente com a utilizaçăo de metodologia que se vale das informaçoes fornecidas pela Imprensa (consulta diária a todos os jornais e formação de arquivo relativo a pessoas que foram vítimas de acidentes e violências, cujas informaç̄̄es são, posteriormente, comparadas às Declaraçoes de Óbitos, completando-as, quando necessário).

Para São Paulo, a situação se apresenta, talvez, menos trabalhosa e de mais fácil solução, visto que, conforme já salientado, o IML dispže da informaçăo. O caminho que se vislumbra como o mais simples, mas talvez o mais demorado - pois vai requerer uma fase não pequena de motivaçăo e treinamento de pessoal - é aquele através do qual o IML comece a preencher as Declaraçōes de Óbito dentro das normas e padrōes desejados. A outra vertente, que poderia ter início, até imediato, seria a representada por uma busca ativa da informação no IML pelo SEADE: à medida que as Declaraçōes de Óbitos chegassem ao SEADE, procedentes dos Cartórios, seriam selecionadas aquelas relativas a causas externas, competindo a essa Instituição ir ao IML, onde procuraria completar os itens não preenchidos, bem como complementar os atestados com todo tipo de informação que não tivesse ali sido transcrita.

Do ponto de vista da prevenção de acidentes, principalmente em crianças, é necessário conhecer as causas no seu maior detalhe, como no citado caso dos atropelamentos, a fim de que os programas de prevençăo possam ser mais bem dirigidos e, portanto, mais eficazes. Esses programas devem estar baseados em dados epidemiológicos que estejam o mais próximo possível do quadro real da região. (Mello Jorge, ${ }^{8,9,10} 1979,1982,1988$ ).

Ao descrever este trabalho foram citados exemplos que ilustram as mudanças referidas, inclusive algumas em nível de capítulo. A Tabela 4 condensa alguns casos que mostram essas situaçōes (codificaçzes feitas segundo a opiniăo do investigador e diferenças entre as informaçōes do IML e do SEADE). 
TABELA 4

Alguns exemplos da casuística relativa à codificação da causa básica de morte segundo as fontes opinião do investigador (O.I.), SEADE e IML (6́bitos por causas externas em menores de 15 anos residentes no Muniớpio de São Paulo, 1985).

\begin{tabular}{|c|c|c|c|}
\hline $\begin{array}{l}N^{0} \text { do } \\
\text { caso }\end{array}$ & $\mathbf{M L L}$ & SEADE & O.I. \\
\hline 005 & Queimaduras & $\begin{array}{l}\text { E } 899 \text { (acidente causado por fogo } \\
\text { não especificado) }\end{array}$ & $\begin{array}{l}\text { E } 924 \text { (acidente causado por } \\
\text { objeto ou substância quente) }\end{array}$ \\
\hline 011 & $\begin{array}{l}\text { Ignorado (traumatismo crâneo- } \\
\text { encefálico a esclarecer) }\end{array}$ & $\begin{array}{l}\text { E } 988 \text { lesão por meios não espe- } \\
\text { cificados em que se ignora se foi } \\
\text { acidental ou intencional) }\end{array}$ & $\begin{array}{l}\text { E } 917 \text { (impacto acidental contra } \\
\text { objeto) }\end{array}$ \\
\hline 020 & $\begin{array}{l}\text { Morte suspeita } \\
\text { (broncopneumonia) }\end{array}$ & 485 (broncopneumonia) & $\begin{array}{l}\text { E } 876 \text { (outros acidentes durante a } \\
\text { prestação de cuidados médicos) }\end{array}$ \\
\hline 055 & Asfixia mecânica & $\begin{array}{l}\text { E } 957 \text { (suicídio por precipitaçāo } \\
\text { de lugar elevado) }\end{array}$ & $\begin{array}{l}\text { E } 882 \text { (queda acidental de jane- } \\
\text { la) }\end{array}$ \\
\hline 096 & $\begin{array}{l}\text { Suicídio por constriçăo do } \\
\text { pesoopo }\end{array}$ & $\begin{array}{l}\text { E } 953 \text { (suicidio por estrangula- } \\
\text { mento ou sufocaçăo) }\end{array}$ & $\begin{array}{l}\text { E } 963 \text { (homicidio por estrangula- } \\
\text { mento, enforcamento) }\end{array}$ \\
\hline 156 & $\begin{array}{l}\text { Traumatismo crâneo-encefálico } \\
\text { por acidente de moto }\end{array}$ & $\begin{array}{l}\text { E } 819 \text { (acidente de trânsito de } \\
\text { veículo a motor não especificado) }\end{array}$ & $\begin{array}{l}\text { E } 968 \text { (homicídio por atropela- } \\
\text { mento) }\end{array}$ \\
\hline 296 & Homicídio? Asfixia + estupro & $\begin{array}{l}\text { E } 983 \text { (lesão por estrangulamento } \\
\text { em que ingnora se foi acidental } \\
\text { ou intencional }\end{array}$ & $\begin{array}{l}\text { E } 963 \text { (homicídio por estrangula- } \\
\text { mento e enforcamento - sufo- } \\
\text { cação) }\end{array}$ \\
\hline 300 & Asfixia. Morte suspeita & $\begin{array}{l}\text { E } 983 \text { (lesão por estrangulamento } \\
\text { ou enforcamento em que se ignora } \\
\text { se foi acidental ou intencional) }\end{array}$ & $\begin{array}{l}\text { E } 913 \text { (sufocação mecânica aci- } \\
\text { dental) }\end{array}$ \\
\hline 370 & $\begin{array}{l}\text { Osteomielite crônica conseqüen- } \\
\text { te a queda atingindo os ossos da } \\
\text { calota craniana }\end{array}$ & 730 (osteomielite) & $\begin{array}{l}\text { E } 929 \text { (efeitos tardios de lesão a- } \\
\text { cidental) }\end{array}$ \\
\hline 396 & Morte a esclarecer & 799 (causa desconhecida) & $\begin{array}{l}\text { E } 920 \text { (acidente causado por ob- } \\
\text { jetos cortantes ou penetrantes) }\end{array}$ \\
\hline 555 & Entrevero com a polícia & $\begin{array}{l}\text { E } 965 \text { (homicidio por arma de fo- } \\
\text { go) }\end{array}$ & $\begin{array}{l}\text { E } 970 \text { (lesão por intervenção le- } \\
\text { gal com arma de fogo) }\end{array}$ \\
\hline 572 & Ferimento por arma de fogo & $\begin{array}{l}\text { E } 968 \text { (ataque por procedimento } \\
\text { não especificado) }\end{array}$ & $\begin{array}{l}\text { E } 922 \text { (acidentes causados por } \\
\text { arma de fogo) }\end{array}$ \\
\hline 912 & Morte suspeita & 789 (encontrado morto) & $\begin{array}{l}\text { E } 968 \text { (ataque causado por meios } \\
\text { não especificado). }\end{array}$ \\
\hline
\end{tabular}

Puderam ser verificados ainda alguns outros tipos de problemas, tais como:

- dos 499 casos examinados, houve $86(17,23 \%)$ em que a codificação dada pelo SEADE foi a correspondente a "acidentes não especificados" (E-928.9 da (ID-9); na opinião do investigador estiveram nesse grupo somente $0,55 \%$ das mortes;

- em 11 casos $(2,20 \%)$ as Declaraçōes tiveram a causa básica da morte codificada com 789.9, categoria que se refere simplesmente ao "encontrado morto". Na realidade, O SEADE parece näo se ter dado conta de que se tratava de uma causa externa e não natural e que a codificação deveria ser dada de acordo com Classificação Suplementar de Causas Externas (código E), visto que o caso fora necropsiado no IML;

- na maioria dos casos em que havia menção, simplesmente, a "Queimaduras" na Declaração de óbito, as causas básicas foram consideradas como decorrentes de "acidentes causados por fogo e chamas" quando, na realidade, muitas vezes eram conseqüentes a "acidentes causados por substância quente";

- algumas vezes em que o IML - tentando esclarecer a modalidade, por exemplo, do acidente de transporte ocorrido, anotava "atropelamento por trem", os casos eram simplesmente considerados como decorrentes de "atropelamento";

- houve mais de um caso codificado oficialmente como "broncopncumonia", quando, na verdade, havia, ao menos no IML, menção à causa externa de morte;

- pelas estatísticas oficiais não se verificou nenhum caso rotulado como "síndrome da criança espancada e outras formas de maus tratos" (E-967) sendo que, segundo a opinião do investigador, 11 casos fizeram parte dessa categoria. 


\section{CONSIDERAÇÕES FINAIS}

O estudo dos 499 óbitos por causas externas em menores de 15 anos residentes no Município de São Paulo, cujas Declaraçōes de Óbitos puderam ser localizadas na Fundação SEADE, permitiu concluir, com relação à causa básica da morte; que:

$\left.1^{9}\right)$ a informação existente no IML esteve bastante próxima da opinião do investigador $(71,54 \%)$, quando se considerou o nível de categoria, chegando a $84,77 \%$, quando se trabalhou em nível de agrupamento;

$\left.2^{2}\right)$ as estatísticas oficiais (SEADE), medidas em relação à opinião do investigador, também são mais fidedignas quando analisadas em nível de agrupamento do que de categoria (respectivamente $67,13 \%$ e $24,05 \%$ de concordância);

$3^{\circ}$ ) a comparação entre IML e SEADE, em nível de terceiro dígito, só mostra $40 \%$ de concordância. Esse valor elevou-se a quase $75 \%$ quando as mortes foram analisadas segundo os agrupamentos da CID-9.

Os valores apresentados comprovam as hipóteses formuladas de que o IML, embora possua um arquivo com informaçశes bem detalhadas a respeito de cada morte, não as transfere ao SEADE, via Declaração de Óbito. Essa Instituição, por sua vez, parece não ter mostrado interesse em procurar o IML para tentar corrigir a falta.

Os aspectos levantados e discutidos mostram que, com relação às causas externas de morte - ao menos na população examinada de menores de 15 anos -, as estatísticas oficiais deixam a desejar. Imaginando que o mesmo fato aconteça relativamente aos 6 bitos de pessoas de 15 anos e mais, conclui-se que a situação é precária e está a exigir açoes urgentes, no sentido de revertê-la, a fim de que os dados possam scr melhor e efetivamente utilizados em programas específicos para a prevenção de mortes por acidentes e violência, entre nós.
Os dados permitem concluir que a situação se apresenta como um grave problema de informação para a saúde, problema esse que está a exigir açōes imediatas para a sua soluçăo. Na realidade, almeja-se que a informação oficial deva permitir atender a esse requisito, para nåo se ter que, a cada momento, despender quantias não desprezíveis de tempo e dinheiro, na realização de pesquisas de campo.

Os institutos de medicina legal (IMLs) do país devem possuir, para cada caso ali necropsiado, uma cópia do Boletim de Ocorrência Policial BO - passado pela Delegacia de Polícia que atendeu ao evento; quando isso não ocorrer, deve existir, ao menos, um documento oficial (por exemplo, telex) da Dclegacia, quando da solicitação de carro para a remoção do corpo para aquela Instituição. O médico que realiza a necrópsia, ao elaborar o seu laudo, deve colocar como causa terminal a natureza da lesão que levou à morte, não deixando, entretanto, de fazer menção ao tipo de acidente ou violência (constante dos documentos citados) que originou as lesões que levaram à morte.

Em face desses problemas, sugere-se empenho dos órgãos de saúde junto aos IMLs no sentido de que os legistas, não só sejam orientados sobre a importância de Declaração de Óbito - com a informação completa sobre cada caso (por exemplo, politraumatismo conseqüente a atropelamento por trem; traumatismo crânio-encefálico conseqüente a suícidio por arma de fogo), mas sejam informados de que, para que não venham a ter envolvimentos futuros com autoridades policiais ou judiciais, anotem na Declaração de Obito a fonte de onde tiraram o dado ali transcrito (número do Boletim de Ocorrência e da Delegacia de Polícia que o emitiu, ou da requisição (ou telex) que chegou da Delegacia ao IML).

Somente dessa maneira será possível a obtenção de dados mais precisos quanto às causas externas, a fim de que, com melhores estatísticas oficiais, efetivos programas de prevenção dessas mortes venham a ser realizados. 
MELLO JORGE, M. H. P. de [Present situation of official statistics related to death from external causes]. Rev. Saúde públ., S. Paulo, 24: 207-23, 1990.

ABSTRACT: A study was carried out on the basis of research data of the deaths due to all kinds of accidents and violence of 550 children of less than 15 years of age, resident in the municipality of $S$. Pau10, State of S. Paulo, Brazil, which occurred during 1985. The project sought to correlate the existing data of the files of the Institute of Legal Medicine (IML) with those of SEADE Foundation (official statistics) and then compare them with the investigator opinion (this latter based on all the additional information available) with a view to: analysing the reliability of the official statistics concerning the main cause of death; and discovering the possible deficiency in the transcription of the IML information to the SEADE Foundation in relation to the same cause. The results are as follows: existing IML information stands quite close to the interviewer's opinion (71.54\%) when working at the level of the categories of the International Classification of Diseases (ICD-9), reaching $84.77 \%$ of agreement when grouping level is considered; in relation to the interviewer's opinion, official statistics proved to be more reliable when analysed at the grouping level than that at the 3rd digit $(67.13 \%$ and $24.05 \%$, respectively); comparison between IML and SEADE Foundation data shows only $40 \%$ of agreement concerning the ICD-9 categories, reaching 75\% when grouping data are analysed. These figures corroborate the proposed hypothesis that the IML, though having files with highly-detailed information, does not transfer them to the SEADE Foundation, thus diminishing the reliability of the official statistics when the details of each cause of death are considered. Better liaison between the two institutions is suggested with a view to achieving statistics of better quality with regard to death from external causes.

KEYWORDS: Cause of death. Accidents. Violence. Vital registration.

\section{REFERÊNCIAS BIBLIOGRAFICAS}

1. CLASSIFICAÇÃO Intemacional de Doenças; 9: Revisāo, 1975. São Paulo, Centro Brasileiro de Classifjcação de Doenças, 1978/79. 2v.

2. CLASSIFICAÇÃO Intemacional de Doenças; 9' Revisão, 1975: Adaptação para o Brasil - CID-BR. Brasília, Ministério da Saúde, 1978.

3. FONSECA, L. A. M. \& LAURENTI, R. Qualidade de certificação da causa da mortalidade em São Paulo. Rev. Saude públ., S. Paulo, 8: 21-9, 1974.

4. GUIMARÃES, C. et al. Mortalidade de adultos de 15 a 74 anos de idade em São Páulo, Botucatu e São Manuel (Brasil), 1974/1975. Rev. Saúde públ., S. Paulo, 13 (Supl. 2), 1979.

5. LAURENTI, R. \& MELLO JORGE, M. H. P. O atestado de óbito. $2^{\star}$ ed. São Paulo, Centro Brasileiro de Classificação de Doenças, 1987.

6. MELLO JORGE, M. H. P. Mortalidade por causas violentas no Município de São Paulo. São Paulo, 1979.[Tese de Doutoramento - Faculdade de Saúde Pública da USP].

7. MELLO JORGE, M. H. P. Mortalidade por causas violentas no Município de São Paulo. IV - A situação em 1980. Rev. Saúde públ., S. Paulo, 16: 19-41, 1982.

8. MELLO JORGE, M. H. P. Investigação sobre a mortalidade por acidentes e violências na infância. São
Paulo, 1988. [Tese de Livre-Docência - Faculdade de Saúde Pública da USP].

9. MILANESI, M. L. \& LAURENTT, R. Estado atual da certificação médica da causa de óbito. Rev. Ass. méd. bras., 10: 111-6. 1964.

10. MINISTÉRIO DA SAĆDE. Manual de instruçōes para o preenchimento da declaraçío de óbitos. Brasilia, 1977.

11. MDISTÉRIO DA SAUDE. Estalísticas de mortalidade, Brasil, 1980/1985. Brasília, 1983/1988.

12. PEXXOTO, H. C. G. O uso de informaçð̃es complementares na codificação da causa básica de óbitos. Florianópolis, 1987. [Apresentado na 2* Reunião Nacional do Sub-Sistema de Informação sobre Mortalidade, Brasília, 1987].

13. PUFFER, R. R. \& GRIFFITH, G. W. Caracteristices de la mortalidad urbana. Washington, D. C., Organización Panamericana de la Salud, 1968. (OPAS Publicación Cienúfica, 151).

14. PUFFER, R. R. \& SERRANO, C. V. Caracteristicas de la mortalidad en la niñez. Washington, D. C., Organización Panamericana de la Salud, 1973. (OPAS Publicación Científica, 262).

Recebido para publicação em 22/9/1989 Aprovado para publicação em 23/1/1990 